Como citar: GOUVEIA, Samuel Moreira. Kelsen e a Teoria da Interpretação Humpty Dumpty. Revista do Direito Público. Londrina, v.11, n.1, p.227-240, jan/ abr.2016. DOI: 10.5433/1980$511 \mathrm{X} .2016 \mathrm{v} 11 \mathrm{n} 1 \mathrm{p} 227$. ISSN: 1980-511X.
* Doutorando pela Université Paris Ouest, em cotutela com a Pontifícia Universidade Católica de São Paulo. Mestre em Direito Público pela Université Pierre Mendès France - Grenoble II. Professor da Faculdade Autônoma de Direito FADISP. E-mail: samuel. gouveia@gmail.com

\section{Kelsen e a Teoria da Interpretação Humpty Dumpty}

\section{KELSEN AND THE THEORY OF INTERPRETATION Humpty Dumpty}

\section{* Samuel Moreira Gouveia}

Resumo: O presente artigo pretende tirar as consequências do desenvolvimento teórico dos conceitos da teoria kelseniana, tomando como foco a relação entre "validade" e "interpretação", para observar a motivação do porque este tipo de crítica leva à consideração necessária da existência de uma pluralidade de atores jurídicos. Toma o redimensionamento realizado por Michel Troper como paradigma daquele desenvolvimento teórico que tem como ponto de partida a resposta insatisfatória dada pela hierarquia piramidal a qual a teoria kelseniana se baseia. Por fim, coteja a relação das diversas teorias face à impossibilidade de existência de uma "língua autônoma", na forma descrita por Wittgenstein nas Investigações Filosóficas.

Palavras-chave: Kelsen, Troper, Wittgenstein, interpretação, validade

Abstract: This article aims to draw the consequences of the theoretical development of the concepts of kelsenian theory focused on the relationship between "validity" and "interpretation" - to observe the motivation this kind of criticism leads to the necessary consideration about the existence of a plurality of legal actors. It takes the theoretical resizing done by Michel Troper as a paradigm of the theoretical development that has its starting point from the unsatisfactory reply given by the pyramidal hierarchy which kelsenian theory is based in. Finally, collates of the various theories face the impossibility of existence of an "autonomous language", as described by Wittgenstein's Philosophical Investigations.

Keywords: Kelsen, Troper, Wittgenstein, interpretation, validity 


\section{INTRODUÇÃO}

Dentre os vários desafios enfrentados por Kelsen, na elaboração de sua Teoria Pura do Direito, um dos mais notáveis é a tentativa de suplantar de forma coerente o sofisma naturalista apresentado por Hume ${ }^{1}$. Nele, o filósofo inglês demonstra a impossibilidade de derivação lógica entre uma proposição descritiva - de uma proposição que descreve um ser (is) - e uma proposição prescritiva - de uma proposição que prescreve um dever ser (ought). Assim, a enunciação de um "dever ser" resulta somente de um ato de vontade, de um julgamento sobre os fatos, jamais da descrição dos fatos em si.

É com tal problema que se depara Kelsen: o Direito, como dever ser (sollen), não pode se fundamentar em um ser (sein). O Direito como - conjunto de - norma(s) deve defluir sempre de outra norma, nunca de um fato (KELSEN, 1999, p. 194). Como é sabido, a resposta de Kelsen para o referido obstáculo epistemológico é a construção teórica da "norma fundamental", ora considerada como hipótese (KELSEN, 1999, p.194) ora considerada como ficção (KELSEN 1986, p. 344-345), nos moldes elaborados por Hans Vaihinger (2011). É a norma fundamental, como imaginada por Kelsen, que dá a condição de cognoscibilidade ao Direito. É dela que irradia a validade para as demais normas do sistema jurídico, é a partir dela que o "todo" do direito pode ser compreendido como objeto da ciência do Direito.

A validade se presta a um triplo papel comumente sintetizado da seguinte forma. Primeiramente, a validade funciona como critério de existência do direito, de tal maneira que "direito válido" é o direito existente, direito positivo, único objeto de estudo da Ciência do Direito. Desse ponto de vista, validade, obrigatoriedade $^{2}$ e existência são termos que se confundem, podendo ser intercambiados livremente. Em segundo lugar, a validade é o critério de pertencimento de uma norma a um sistema normativo. Ou seja, a qualidade

\footnotetext{
Em todo sistema de moral que até hoje encontrei, sempre notei que o autor segue durante algum tempo o modo comum de raciocinar, estabelecendo a existência de Deus, ou fazendo observações a respeito dos assuntos humanos, quando, de repente, surpreendo-me ao ver que, em vez das cópulas proposicionais usuais, como é e não é, não encontro uma só proposição que não esteja conectada a outra por um deve ou não deve. Essa mudança é imperceptível, porém da maior importância. Pois como esse deve ou não deve expressa uma nova relação ou afirmação, esta precisaria ser notada e explicada; ao mesmo tempo, seria preciso que se desse uma razão para algo que parece totalmente inconcebível, ou seja, como essa nova relação pode ser deduzida de outras inteiramente diferentes." (HUME, 2000, p. 509).

2 Uma crítica sobre a identificação entre validade e obrigatoriedade da norma jurídica pode ser vista em Gouveia (2015).
} 
"válida" predicada à uma norma equivale a afirmação de que esta norma pertence à algum sistema normativo. Por fim, em terceiro lugar, a validade é o critério de identificação de uma norma a um sistema específico. Informar a validade de uma norma significa mais do que a mera necessidade de pertencimento a qualquer sistema normativo, mas o pertencimento específico, de forma exclusiva: a norma valida é norma de um e apenas um sistema normativo, a exclusão dos demais.

De outro lado, relegado a um plano secundário na obra do mestre de Viena, o conceito de "interpretação" aparentemente não se relaciona ao tema da "validade" e não animou, inicialmente, maiores desenvolvimentos teóricos e críticos a respeito da solução ao sofisma naturalista de Hume. Desenvolvido em uma dezena de páginas no capitulo VI da primeira edição da Teoria Pura, publicada em 1934 (1997) e confinada ao último capítulo de sua segunda edição, de 1960 (1999), só tardiamente o conceito kelseniano de "interpretação" despertou interesses teóricos. Em uma dessas ocasiões, na década de 1980, em releitura à teoria kelseniana, Michel Troper chamou a atenção sobre a relação umbilical entre estes dois conceitos, validade e interpretação, organizando sua teoria como base neste ponto da teoria da teoria do mestre de Viena.

O presente ensaio pretende tirar algumas consequências epistemológicas e cognoscitivas do desenvolvimento de conceitos da teoria kelseniana, aqui focalizado precisamente na relação entre "validade" e "interpretação", para observar que este tipo de crítica leva à necessidade da existência de uma pluralidade de atores jurídicos, igualmente conhecidos por "produtores do direito". Toma-se o redimensionamento realizado pela teoria de Michel Troper apenas como paradigma do desenvolvimento teórico ${ }^{3}$ que parte da resposta insatisfatória dada pela teoria kelseniana face à impossibilidade de existência de uma "língua autônoma".

\section{O REDIMENSIONAMENTO DA TEORIA DA INTERPRETAÇÃO DE KELSEN: UMAPORTE TROPERIANO}

Quando se adentra na teoria da interpretação kelseniana, encontra-se de pronto como obstáculo a imprecisa relação entre "interpretação" e "norma jurídica". Em uma das primeiras formulações apresentadas na segunda edição da Teoria Pura do Direito, Kelsen (1999, p.13) afirma que a norma seria $a$

\footnotetext{
3 Interessante observar que traços destes desenvolvimentos teóricos podem igualmente ser encontrados em autores tão distintos e de outras vertentes tão diferentes, como Friedrich Müller (2009) e Eros Roberto Grau (2014).
} 
significação de um ato humano, pelo qual uma conduta é prescrita, permitida ou, de forma particular, habilitada. Ocorre que, em outras partes da mesma obra, o autor trata a própria norma não como produto do processo interpretativo - significação - mas sim como seu objeto, quando, por exemplo, trata das diferentes possíveis significações linguísticas da norma jurídica (KELSEN, 1999, p.337). Tal imprecisão na linguagem é amplamente conhecida e mesmo o mestre austríaco retorna o assunto, de forma mais precisa, em sua obra póstuma, Teoria Geral das Normas, de 1979, onde demonstra sua preferência pela concepção de que a norma é um significado ${ }^{4}$ - e não possui uma significação ${ }^{5}$.

De fato, se interpretar é atribuir significado a um significante (GUASTINI, 2004), quando a norma ostenta o status de significado, não pode ser interpretada. Assim é, pois a norma jurídica figura como ponto de chegada no processo interpretativo e não como seu ponto de partida. Para que isso ocorra, para que a "norma" tenha um "significado", o significado - a norma deve adquirir outro status e tornar-se significante - disposição normativa, texto. Só a partir deste momento há a possibilidade de sua (re)figuração ou (re)significação como objeto do processo interpretativo, aí não mais como significado, mas como significante. Como afirma Eco (1994, p. 368), "Interpretar significa reagir ao texto do mundo e ao mundo de um texto, produzindo outros textos".

É, assim, o texto - constituição, lei, decreto, etc... - e não a norma, o objeto do processo de interpretação. A norma é o resultado da interpretação. Como bem demonstra Guastini (2004, p. 11 e 12), se a interpretação fosse entendida de outra forma, nos moldes cognitivistas, se criaria uma falsa impressão de que o significado do texto normativo já estaria inteiramente constituído antes mesmo da interpretação, hipótese que não se conforma na própria Teoria Pura.

Ora, se a norma é o produto da atividade interpretativa - em outras palavras, uma significado - quem produz esta interpretação? Um primeiro

\footnotetext{
${ }^{4}$ No presente ensaio, utiliza-se os termos "significado" e "sentido" de forma indiscriminada. Para uma posição distinta, que demarca a diferença entre estes termos, ver Émile Benveniste (1974) e Paul Ricoeur (2005).

5 "Como se depreende do que procedeu, urge distinguir-se entre um ato de comando, de prescrição, de fixação de norma, que é um ato de vontade e, como tal, tem o caráter de evento, i.e., do ser, e entre o mandamento, a prescrição, a norma, como também entre o sentido desse ato, e isto significa: um dever ser. Mais corretamente diz-se: a norma é um sentido, em vez de: a norma tem um sentido. O ato de vontade, como ato do ser, "tem" o sentido de um dever-ser. Este dever-ser é a norma." (KELSEN, 1986, p. 34).
} 
traço desta resposta pode ser encontrado na distinção feita por Kelsen (1999, p. 10 e 11) entre significação subjetiva e significação objetiva. Os indivíduos, quando agem, impregnam suas ações de determinados propósitos ou significados, eis a significação subjetiva. A significação subjetiva seria então aquela dada ao ato pelo indivíduo que age. Já a significação objetiva é aquela dada pelo direito, em conformidade com o direito. Nota-se que a significação subjetiva pode, mas não necessariamente está, de acordo com sua significação objetiva. O exemplo do testamento, dado por Kelsen (1997) no início da Teoria Pura do Direito, ilustra bem a possibilidade da existência de conflitos entre os tipos de significação: se algumas disposições estatuindo a forma da partilha dos bens do testamenteiro após sua morte têm como significação subjetiva um testamento, objetivamente, a inobservância de determinadas formalidades pode acarretar a não coincidência entre a significação objetiva e sua significação subjetiva, tornando-se, assim, imprestável ao fim jurídico proposto em sua elaboração.

Se, de fato, a distinção entre significação objetiva e subjetiva é uma resposta inconclusiva, pois a pergunta de quem realiza a interpretação objetiva ainda permanece em aberto, o caráter insatisfatório desta classificação persiste até o último capítulo da Teoria Pura do Direito. Somente nele que se vislumbra o que Kelsen entende por "interpretação". Bem que a teoria kelseniana da interpretação tem sido acusada de pouca originalidade, quando observada de perto, traz algumas elaborações relevantes para a compreensão da teoria pura como um todo. Tais elaborações podem ser resumidas da forma a seguir.

Primeiramente, na doutrina tradicional, a "interpretação autêntica" se refere à interpretação do texto pelo próprio autor. Já Kelsen entende, por essa expressão, a interpretação realizada pelo órgão de aplicação do direito, em contraposição à ciência do direito. Na distinção acima, entre significação objetiva e subjetiva, pode-se dizer que o produto da interpretação pelos órgãos de aplicação seria a significação "objetiva" - aquela dada pelo direito. São as autoridades que dão contornos à norma jurídica aplicada e, por exclusão, as que não emanam das autoridades no processo de aplicação podem ser consideradas "subjetivas".

Outro ponto a sublinhar é a retirada de foco de uma certa relação entre judiciário e interpretação bem arraigada na doutrina. A doutrina tradicional entendia que a interpretação só deveria ser utilizada para desvendar enunciados dúbios, segundo o princípio In claris non fit interpretatio. Quando o texto era claro, o papel do aplicador era o de apenas aplicar o que era expresso no 
texto ${ }^{6}$. Ao contrário, para o autor da teoria pura, a interpretação autêntica acompanha necessariamente o processo de aplicação em sua progressão (KELSEN, 1999, p. 335): a interpretação passa a ser criadora do direito (KELSEN, 1999, p. 340), no sentido em que o órgão de aplicação preenche a moldura da norma geral para a produção da norma individual (KELSEN, 1999, p. 337 e 338) ${ }^{7}$. Deste modo, de mera atividade acessória da aplicação do direito, pela caneta de Kelsen o processo interpretativo se torna intrínseco a todo e qualquer ato de criação/aplicação do direito. A interpretação é uma etapa necessária pela qual a aplicação do direito deve passar. Neste tocante, é necessário observar que as distinções descritas possuem uma classificação epistêmica subjacente. Para Kelsen, a interpretação pode ser considerada tanto ato de vontade como ato de conhecimento. É o ato de vontade o criador do direito - auctoritas, non veritas, facit legem: é a autoridade e não a verdade que faz o direito. $\mathrm{O}$ ato de conhecimento, típico da ciência do direito, tem por único papel, a elaboração das inúmeras significações possíveis - criando deste modo uma moldura de significados - que serão escolhidas na ocasião da aplicação do direito (KELSEN, 1999, p. 340).

Com pano de fundo a teoria da interpretação, Troper formula importantes desenvolvimentos à teoria kelseniana. Entre todos os avanços elaborados pelo jurista francês, destacam-se três reflexões importantes em relação ao conceito de interpretação em Kelsen.

Primeiramente, se "interpretar" é "atribuir significado" a um significante, o órgão aplicador não cria somente a norma individual, mas também, e sobretudo, cria a norma geral a aplicar no silogismo judiciário - além do fato a ser subsumido (TROPER, 1981). É o órgão aplicador que interpreta o texto e elabora a norma geral como produto de sua ação interpretativa (TROPER, 1981, p. 523). Além, é o órgão aplicador que seleciona os textos que possuem significados normativos daqueles que não o possuem. Não é desconhecida a decisão do Conseil Constitutionel $^{8}$ francês, que decidiu pelo caráter normativo do preâmbulo da Constituição francesa de 1959, criando assim o bloco de constitucionalidade -

\footnotetext{
${ }^{6}$ Sobre a escola da exegese, ver Hespanha (2005, p. 375 e ss.).

7 Deve-se observar, contudo, que a "aplicação" não se confunde com a "interpretação": as duas atividades possuem objeto distintos. Enquanto a interpretação possui como objeto os textos normativos, a aplicação tem por objeto a norma em sentido estrito. A aplicação não coincide como a interpretação pelo simples fato de que a pressupõe, conforme Guastini (2004, p. 13).

${ }^{8}$ Decisão Liberté d'association de 16 julho de 1971, que começa com palavras audaciosas: "Vu la Constitution et notamment son préambule" (em tradução livre "Visto a Constituição e notadamente seu preâmbulo"). São audaciosas pelo fato de que à época justamente o preâmbulo da Constituição não reputava ter caráter constitucional.
}

Revista do Direito Público, Londrina, v.11, n.1, p.227-240, jan./abr.2016 | DOI: 10.5433/1980-511X.2016v11n1p227 
diversos textos com caráter constitucional. Em terras brasileiras, é notável a decisão do Supremo Tribunal Federal na ADI 2076/AC, onde se decidiu que o preâmbulo da Constituição de 1988 não enseja reprodução obrigatória nas constituições estaduais, o que, por via transversa, corresponde a não conceder normatividade aquele extrato do texto constitucional.

Se a ideia de que a criação da norma geral pelo interprete é muito esclarecedora, ela não se encontra imune a um retoque. Ora, se ao elaborar a decisão, o órgão de aplicação cria a norma geral, visto que esta é fruto de interpretação dos textos legais, o mesmo não pode ser dito da norma individual. Contrariamente ao ensinado pelo mestre francês (TROPER, 1981), o órgão de aplicação não cria a norma individual no mesmo momento que a norma geral. A norma individual só pode ser criada pelo órgão aplicador da sentença dada, é este órgão que interpreta a decisão judicial. Assim, a norma individual está para o texto de sentença no mesmo topos que a norma geral está para o texto da lei.

Em segundo lugar, Troper entende ser problemática a distinção entre "ato de vontade" e "ato de conhecimento" proposta por Kelsen. Assim o é porque não reflete a situação dos tribunais inferiores ou órgãos da administração pública. Se é verdade que estas instâncias podem realizar interpretações, não menos real é o fato de que, estas interpretações devem (re)produzir significações em grande parte idênticas às dadas pelos tribunais superiores. Assim, estas instâncias estão em posição quase análoga aos sujeitos de direito, visto que estes devem conhecer e conformar-se com as significações produzidas pelas cortes superiores para evitar eventuais sanções, já aquelas necessitam conhecer as significações emanadas para que não tenham suas decisões anuladas (TROPER, 1981, p. 523). Nestes casos, a diferenciação entre "conhecimento" e "vontade" não é operatória ${ }^{9}$ em grande parte do fenômeno jurídico estudado pelo Direito.

O conceito de "intérprete autêntico" de Kelsen, na forma demonstrada por Troper, se deslocaria e se limitaria tão somente ao caso das autoridade que se encontram nas últimas instâncias decisórias, figurando como paradigma natural, as cortes supremas. Desse posicionamento deflui, para Troper, que a hierarquia jurídica não deriva da norma superior, mas sim do processo de produção da norma inferior. A significação do ato legislativo é determinada pelo órgão aplicador e assim por diante, no processo de "aplicação" do direito.

\footnotetext{
9 No direito brasileiro, a crítica de Troper é ainda mais pertinente com o advento das súmulas vinculantes prescrito pela Emenda Constitucional $n^{\circ} 45$ e o novo Código de Processo Civil, que parece trazer consigo a vinculação das instâncias inferiores aos julgamentos de casos repetitivos em seu Livro, III, Título I, Capítulo VI.
}

Revista do Direito Público, Londrina, v.11, n.1, p.227-240, jan./abr.2016 | DOI: 10.5433/1980-511X.2016v11n1p227 
Ainda, Troper (2001, p. 110) assinala que as cortes supremas se encontram em posição privilegiada na hierarquia jurídica, visto que dentre todos os enunciados que elas interpretam estão aqueles que lhe conferem seu âmbito de competência. Ao passo que interpreta estes enunciados, a corte determina suas próprias competências, frequentemente para estendê-las. Este é o caso, por exemplo, da Corte dos Estados Unidos quando, em $1803^{10}$, se declarou competente para controlar a constitucionalidade das leis, competência esta que não era considerada expressa no texto constitucional.

Assim, da releitura de Troper sobre a teoria da interpretação kelseniana (TROPER (1981); TROPER; CHAMPEIL-DESPLATS; GRZEGORCZYK, (2005)) deflui que o intérprete autêntico é juridicamente livre para criar o direito - visto como norma jurídica ${ }^{11}$. A liberdade das cortes supremas é devida pela capacidade de produção de decisões sem recurso, ou seja, interpretações que não podem ser juridicamente contestadas e que produzem efeitos, ainda que contra o senso comum ou linguagem ordinária. Mesmo na suposição da existência de uma norma jurídica superior que obrigasse a corte a resolver conflitos pela aplicação de uma determinada regra, na falta de sanção (e de órgão sancionador), tudo se passaria como se não houvesse norma superior.

\section{LÍNGUA E NORMATIVIDADE: DA IMPOSSIBILIDADE DE UMA LINGUAGEM AUTÔNOMA}

A liberdade do intérprete autêntico causa, contudo, certos problemas epistemológicos e se a norma fundamental não é mais a fundação ficcional para a unificação da multiplicidade de tomadas de decisão na criação de normas jurídicas, este espaço "fundante" não pode ficar vago.

Não é fortuito que críticas ao sistema teórico kelseniano, como as de Troper, desaguem na troca da norma fundamental por outro elemento que traga racionalidade - e cognoscibilidade - ao sistema. No caso da teoria troperiana, as críticas acima demonstradas dão aso à sua Théorie de Contraintes Jurídiques $^{12}$. Segundo esta teoria, as contraintes juridiques ${ }^{13}$ explicam que há soluções que se impõem ao ator (interprete autêntico) em razão de uma configuração específica do sistema jurídico (TROPER, 2001, p. 13). Visto de

\footnotetext{
${ }^{10}$ Caso Marbury versus Madison.

${ }^{11}$ Contra essa posição, ver Guastini (2004 e 2008).

${ }^{12}$ Para um resumo mais detalhado da Théorie de Contraintes Juridiques de Troper em português, ver Gouveia (2014).

${ }^{13}$ Traduzido pela expressão "pressões jurídicas" em Gouveia (2014).
} 
outra forma, o intérprete vê que - entre todas as possibilidades interpretativas existentes - somente algumas lhe parecem possíveis. O paralelo do jogador de xadrez é aqui esclarecedor: mesmo sabendo a forma de movimentação de todas as peças do tabuleiro em um determinado momento, ele vê apenas alguns dentre aquelas movimentos como possíveis para atingir seu objeto, os restantes são devidamente descartados. O processo de interpretação é livre, mas não aleatório. Esta racionalidade pressupõe uma diversidade de produtores de normas e uma relação dinâmica entre eles. Em cada decisão deve-se - e este "deve" significa aqui não que o autor está submetido a uma obrigação, mas sim que ele é pressionado - ter em conta os meios que o sistema atribui aos outros atores participantes (tal como responsabilizar, dissolver a Assembleia, revogar uma decisão, etc.) e antecipar a forma com que estes podem se servir em suas ações futuras (TROPER; CHAMPEIL-DESPLATS; GRZEGORCZYK, 2005).

A pluralidade de atores também é fundamento para concepções teóricas tão diferentes da troperiana quanto, por exemplo, as elaboradas por Hart e Van Hoecke. De certa forma, a teoria da open texture hartiana considera como necessário para a existência do sistema jurídico que as regras de competência, por um lado não estejam abertas à dúvida em todos os pontos de vista e pelo outro, que haja a adesão sobre o conteúdo das regras pela maior partes dos julgadores (HART, 2012). Já o jurista belga, partindo da crítica à teoria dos sistemas, entende que a validade, vista como legitimação, é feita pela interação dos vários níveis de instituições, pelo seu reconhecimento recíproco e pelo reconhecimento recíproco de seus produtos (VAN HOECKE, 2002). Descarta assim, a necessidade epistemológica de uma norma básica do tipo kelseniana, visto que o sistema jurídico se sustentaria através da aceitação social das instituições legais entre si.

A visão de um intérprete supremo no cume da ordem jurídica hierarquizada e "pura" passa a dar lugar a concepções do sistema jurídico baseadas em uma diversidade de configurações espacial, que vão da "rede" (OST; KERCHOVE, 2002) ao "arquipélago" (TIMSIT, 1997). Tais configurações têm em comum um caráter decentralizado, distinto do tipo arborescente do qual a pirâmide kelseniana é tributária.

Para além da configuração espacial dos paradigmas apresentados, a adoção da "significação" como conceito central da teoria do direito - por Kelsen e por praticamente a totalidade dos membros da escola normativista e o ganho de importância do modelo epistemológico da linguística/semiótica no século XX nas ciências sociais parecem ser a pedra angular para essa mudança de paradigma na ciência do direito. Isto porque tal desenvolvimento parece ser 
decorrente de uma percepção já há tempos arraigada nos estudos linguísticos e da filosofia da linguagem, de que a língua possui o caráter intrinsicamente social e decentralizado, percepção esta que culmina com a análise realizada por Wittgenstein (1986), sobre a impossibilidade de uso da linguagem de forma totalmente autônoma do processo social.

Para o filósofo austríaco, o sentido - ou significado - de uma palavra ou de um enunciado é estabelecido pelo seu uso em um determinado jogo de linguagem (WITTGENSTEIN, 1986, p. 20 e 21) - através de regras pragmáticas. Já as práticas autônomas seriam aquelas cuja normatividade não dependem de nada além delas mesmas, visto que asseguram sua correção. Essa parece ser a posição das cortes supremas como interpretes autênticos no modelo kelseniano. A inexistência de recursos contra as decisões que produzem as cortes superiores garante a elas a liberdade jurídica na escolha dos significados dos textos interpretados, como a famosa afirmação do juiz Jackson, da suprema corte norte-americana: "Nós não somos a última instância porque somos infalíveis, mas somos infalíveis porque somos a última instância"14. A consequência dessa liberdade seria a impossibilidade de erro na atribuição de significado, ou seja, a infalibilidade na criação de normas jurídicas.

Contudo, no processo de produção de significação, em vez de garantir correção, a infalibilidade destrói quaisquer possibilidades de comunicação, porque estar correto perde sua força, quando a possibilidade de incorreção desaparece. Para Medina (2007, p. 164) “(...) o argumento de Wittgenstein sugere a diferença entre parecer correto e ser correto requer a possibilidade de negociação e correção mútua, que para tanto deve haver diferentes centros de avaliações normativas". Assim, a linguagem vista como um jogo vê suas regras desmoronarem por completo quando o que conta como correto não pode ser contestado (WITTGENSTEIN, 1986, p. 80) ${ }^{15}$.

No sentido observado por Kelsen e redimensionado por Troper, o intérprete autêntico se apresentaria como uma espécie de Humpty Dumpty, personagem de Lewis Caroll (2010) que, ao ser deparado por Alice na sexta casa, na obra "Alice através do espelho", engendra uma discussão ao mesmo

\footnotetext{
14 "We are not final because we are infallible, but we are infallible only because we are final" Opinião concordante no caso Brown v. Alle, 344US 443 (1953).

${ }^{15}$ As análises de Wittgenstein a respeito da linguagem privada podem ser sintetizadas no famoso $\S$ 201 das Investigações Filosóficas: "This was our paradox: no course of action could be determined by a rule, because every course of action can be made out to accord with the rule. The answer was: if everything can be made out to accord with the rule, then it can also be made out to conflict with it. And so there would be neither accord nor conflict here." (WITTGENSTEIN, 1986, p. 80).
}

Revista do Direito Público, Londrina, v.11, n.1, p.227-240, jan./abr.2016 | DOI: 10.5433/1980-511X.2016v11n1p227 
tempo perturbadora e reveladora sobre o tema em questão (CARROLL, 2010, p. 243-244):

"Deram-me a gravata", Humpty Dumpty continuou, pensativo, enquanto cruzava os joelhos e punha as mãos em volta deles, "deram-me... como um presente de desaniversário."

"Perdão?" Alice perguntou, perplexa.

"Não estou ofendido", disse Humpty Dumpty.

"Quero dizer, o que é um presente de desaniversário?"

"Um presente dado quando não é seu aniversário, é claro."

Alice refletiu um pouco. "Gosto mais de presentes de aniversário", declarou finalmente.

"Não sabe do que está falando!" exclamou Humpty Dumpty. "Quantos dias há no ano?"

"Trezentos e sessenta e cinco", disse Alice.

"E quantos aniversários você faz?"

"Um."

"E se diminui um de trezentos e sessenta e cinco, resta quanto?"

"Trezentos e sessenta e quatro, claro."

Humpty Dumpty pareceu duvidar.

"Preferiria ver essa conta no papel", disse.

Alice não pôde conter um sorriso enquanto pegava sua caderneta e armava a subtração para ele.

365

$-1$

364

Humpty Dumpty pegou a caderneta e examinou-a atentamente. "Parece estar correto..." começou.

"Está segurando de cabeça para baixo!" Alice interrompeu.

"Claro que estava!" Humpty Dumpty disse jovialmente, enquanto ela a desvirava para ele. "Pareceu-me um pouco estranho. Como eu ia dizendo, parece estar correto - embora eu não tenha tido tempo de examiná-la a fundo neste instante - e isso mostra que há trezentos e sessenta e quatro dias em que você poderia ganhar presentes de desaniversário..."

"Sem dúvida", disse Alice.

"E só um para ganhar presentes de aniversário, vê? É a glória para você!"” "Não sei o que quer dizer com 'glória", disse Alice.

Humpty Dumpty sorriu, desdenhoso. "Claro que não sabe... até que eu lhe diga. Quero dizer 'é um belo e demolidor argumento para você!"”

"Mas 'glória' não significa 'um belo e demolidor argumento", Alice objetou. "Quando eu uso uma palavra", disse Humpty Dumpty num tom bastante 
desdenhoso, "ela significa exatamente o que quero que signifique: nem mais nem menos."

"A questão é", disse Alice, "se pode fazer as palavras significarem tantas coisas diferentes."

"A questão", disse Humpty Dumpty, "é saber quem vai mandar — só isto."

Para Humpty Dumpty, as palavras significam exatamente o que o ele quer que signifiquem, nem mais nem menos. A semelhança entre o personagem e o conceito de "interprete autentico" é notável. Sem que haja alguma forma de discussão sobre a significação, ambos estão sempre certos e, ao mesmo tempo, terrivelmente errados. Diante de uma espécie de "belo e demolidor argumento" - como diria a personagem ou o juiz Jackson - a língua dissolvese e, com ela, o direito.

Assim, ao intérprete autentico nada pode garantir a sua própria inteligibilidade e correção. Quando tudo está correto, quando não há possibilidade de engano, não se pode estabelecer o correto e o incorreto. A autonomia, ao invés de fazer a normatividade inabalável, a aniquila. O jogo de linguagem, da forma entendida por Wittgenstein, deve conter a possibilidade de estar incorreto na sua pluralidade de núcleos normativos. Deve conter, sobretudo, a possibilidade de negociações normativas, em um processo dialético de contestação e justificação.

\section{CONSIDERAÇÕES FINAIS}

A relação entre a validade e interpretação parece essencial na teoria pura kelseniana. É a interpretação do intérprete autêntico que cria a norma jurídica - objeto de estudo da ciência do direito na forma compreendida pelo positivismo normativista. Contudo, os avanços trazidos pelos ensinamentos da teoria realista de Troper, que leva a sério os conceitos empregados por Kelsen, parecem demonstrar a impossibilidade da criação de uma ciência normativa nos moldes estruturados pelo mestre de Viena pelo fato de seu objeto desmontarse por cima de si mesmo, como um castelo de cartas sem sua base de sustentação.

Este fato deve-se principalmente pela observação de apenas um lado na moeda. Como observado no exemplo da teoria troperiana, se de fato as cortes constitucionais são juridicamente livres - visto que não há forma jurídica de discutir suas decisões - é necessário observar sua contraparte, a que de certa 
forma, não torna suas decisões arbitrárias. Liberdade jurídica e arbitrariedade não podem ser identificadas aqui.

Esta contraparte se concretiza com a existência de uma pluralidade de atores no jogo social/jurídico. Uma crítica ao conceito kelseniano de sistema jurídico passa então pela crítica ao seu conceito de produção de significação nomogênese -, de interpretação e da própria noção de sistema. Se o sistema jurídico é autônomo, como entende Kelsen, esta autonomia só pode ser relativa, visto o direito ser um subsistema contido em um sistema significante ainda maior: a sociedade. Sistema social e contratualismo, eis nosso mitologema, eis um tema que ainda não há impenetrabilidade.

\section{REFERÊNCIAS}

\section{CARROLL, Lewis. Aventuras de Alice no País das Maravilhas \&} Através do espelho e o que Alice encontrou por lá. São Paulo: Zahar, 2010.

ECO, Umberto. Les limites de i'interprétation. Paris: Les livres de Poche, 1994.

GUASTINI, Riccardo. L'interpretazione dei documenti normativi. Milão: Dott. A. Giufrè Editore, 2004.

HART, Herbert Lionel Adolphus. The concept of law. 3. ed. Oxford: Oxford University Press, 2012.

HESPANHA, António Manuel. Cultura jurídica européia: síntese de um milênio. Florianópolis: Fundação Boiteux, 2005.

HUME, David. Tratado da natureza humana: livro III, parte I, seção II. São Paulo: Editora UNESP, 2000.

KELSEN, Hans. Introduction to the problems of legal theory. Oxford: Oxford University Press, 1997.

Théorie générale des normes, Paris: PUF, 1996. Tradução brasileira: Teoria geral das normas. Porto Alegre: Sérgio Fabris Editor, 1986. 
Théorie pure du droit, Paris : L.G.D.J., 1999.

MEDINA, José. Linguagem: conceitos-chave em filosofia. Porto Alegre: Artmed, 2007.

MÜLLER, Friedrich. O novo paradigma do direito: introdução à teoria e metódica estruturantes. 2. ed. São Paulo: Revista dos Tribunais, 2009.

RICOEUR, Paul. Discours et communication. Paris: L'Herne, 2005.

TIMSIT, Gérald. L’archipel de la norme. Paris: PUF, 1997.

TROPER, Michel, Kelsen. La théorie de l'interprétation et la structure de l'ordre juridique. Revue Internationale de Philosophie, Paris, n. 138, p. 518-529, 1981.

Philosophie du droit. Paris: PUF, Collection Que sais-je ?, 2001.

TROPER, Michel, CHAMPEIL-DESPLATS Véronique et GRZEGORCZYK, Christophe. (dir). Théorie des contraintes juridiques. Paris : LGDJ, 2005.

VAIHINGER, Hans. A filosofia do como se. Chapecó: Argos, 2011.

VAN HOECKE, Mark. Law as communication. Oxford: Hart Publishing, 2002.

WITTIGENSTEIN, Ludwig. Philosophical investigations. Oxford: Basil Blackwell Ltd., 1986.

Artigo recebido em: 15/03/2016 Aprovado para publicação em: 28/03/2016

Como citar: GOUVEIA, Samuel Moreira. Kelsen e a Teoria da Interpretação Humpty Dumpty. Revista do Direito Público. Londrina, v.11, n.1, p.227-240, jan/abr.2016. DOI: 10.5433/1980-511X.2016v11n1p227. ISSN: 1980-511X. 